\title{
Utilities of Botulinum Toxins in Dermatology and Cosmetology
}

Piyu Parth Naik (D)

Department of Dermatology, Saudi German Hospital and Clinic, Dubai, United Arab Emirates
Correspondence: Piyu Parth Naik Department of Dermatology, Saudi German Hospital and Clinic, Opposite Burj Al Arab, Dubai, United Arab Emirates

$\mathrm{Tel}+97 \mid 503725616$

Email drpiyu85@gmail.com

\begin{abstract}
Botulinum toxin (BoNT) is a neurotoxin produced by the Clostridium botulinum bacterium with a well-known efficacy and safety profile in the focal idiopathic hyperhidrosis treatment. BoNT comprises seven different neurotoxins; however, only toxins A and B are clinically employed. BoNT is lately practiced in off-label therapies for a variety of skin diseases. Scar prevention, hyperhidrosis, rhytides, eccrine nevus, alopecia, psoriasis, Darier disease, bullous skin disease, pompholyx and Raynaud's phenomenon are some of the novel indications for BoNT in cosmetic and notably non-cosmetic aspects of dermatology. To employ BoNT correctly in clinical practice, we must have a thorough understanding of the functional anatomy of the mimetic muscles. An intensive literature search was conducted to update all dermatology-oriented experiments and clinical trials on the described element of BoNT for this general overview of BoNT use in dermatology. This review aims to analyse the role of BoNT in dermatology and cosmetology.
\end{abstract}

Keywords: botulinum toxin, BoNT, Clostridium botulinum, dermatology, cosmetology, neurotoxin

\section{Introduction}

Botulinum neurotoxin (BoNT) is produced naturally by Clostridium botulinum, an anaerobic, Gram-positive, spore-forming bacillus. ${ }^{1}$ So far, seven serotypes of BoNT have been discovered ( $A$ to $G$ ), with only types $A$ and $B$ available for therapeutic usage. BoNT A (Oculinum) was approved by the Food and Drug Administration (FDA) in 1989 to treat blepharospasm and strabismus, the therapeutic value of BoNT A was first identified. The FDA did not authorize the use of BoNT A for the treatment of glabellar lines until April 2002. BoNT A was authorized by the FDA in October 2017 and September 2013 for the forehead lines and lateral canthal lines treatment, respectively. Several BoNT formulations have been introduced to the market since then. ${ }^{2}$ BoNTs have been used for spasticity, depression, hyperhidrosis, migraines, and aging of the neck, face, and decolletage on and off label in the medical and cosmetic areas since their commercial availability. 3,4

C. botulinum secretes a three-protein complex that includes a $150 \mathrm{kDa}$ toxin, a nontoxic, non-haemagglutinin protein, and a non-toxic haemagglutinin protein. Bacterial proteases break the toxin into a di-chain active product with $50 \mathrm{kDa}$ "light" and $100 \mathrm{kDa}$ "heavy" chains. After already being transported to the presynaptic nerve terminal, the active toxin's heavy chain binds to synaptic vesicle glycoprotein 2, precipitating endocytosis of the toxin-glycoprotein complex and release of the toxin light chain into the synaptic space. Toxin light chains cleave vesicle-associated membrane protein/ 
synaptobrevin (BoNT-B, D, F, G) or synaptosomal-associated protein 25 (BoNT-A, C, E), preventing acetylcholine release from peripheral motor neuron axons and resulting in transient chemical denervation and muscle paralysis. ${ }^{2}$ In the United States, there are four commercially available, FDA-approved BoNT-A formulations: incobotulinumtoxinA (Frankfurt, Germany), onabotulinumtoxinA (California, USA), prabotulinumtoxinA-xvfs (California, USA) and abobotulinumtoxinA (Arizona, USA); as well as one BoNTB: rimabotulinumtoxinB (California, USA). ${ }^{5} \mathrm{~A}$ review by Guida et $\mathrm{al}^{6}$ evaluated the role of BoNT in the field of dermatology. However, recently there are no reviews conducted on the application of BoNT in the field of dermatology and cosmetology. Therefore, the current review aims to analyse the role of BoNT in dermatology and cosmetology.

\section{Methodology}

With the specific keywords including botulinum toxin, oily skin, rosacea, facial flushing, scar, rhytides, alopecia, psoriasis, bullous skin disease, Darier Disease, eccrine nevus, pompholyx, Raynaud's phenomenon, hyperhidrosis adverse effects, dermatology and cosmetology, an article search was conducted in the following databases: Google Scholar, PubMed, MEDLINE, Scopus, and Cochrane. The author was mainly looking for articles on the role of BoNT in dermatology and cosmetology. The initial literature search revealed 3112 articles. Articles published between the years January 1990 and July 2021 with a description of BoNT in dermatology and cosmetology, articles published in the English language, and all study designs were included in this review.

\section{Role of BoNT in Cosmetology}

The use of BoNT for localized muscle spasticity and aesthetic treatment of wrinkles at the brow line was approved in Canada in 2000. The US FDA approved the use of BoNT for cosmetic purposes on April 15, 2002. Recent BoNT-A indications for cosmetics applications include glabellar frown lines, crow's feet, bunny lines, horizontal forehead lines, perioral lines, mental crease and dimpled chin, platysmal bands, mouth frown and horizontal neck lines. ${ }^{7}$ The US FDA approved indications of onabotulinum type A are moderate-to-severe glabellar frown lines associated with procerus and/or corrugator muscle overactivity, moderate-to-severe lateral canthal lines associated with orbicularis muscle overactivity, and moderate-to-severe horizontal forehead lines associated with frontalis overactivity. ${ }^{8}$

\section{BoNT in Oily Skin}

Sebum helps supply fat-soluble antioxidants to the skin's surface and contains antibacterial properties; thus, it acts as a skin barrier. Excess sebum block pores feed germs and can cause skin inflammation (eg, seborrheic dermatitis, acne). Previously, relevant knowledge about the effect of BoNT on sebum production was revealed..$^{9,10}$ Rose and Goldberg ${ }^{10}$ tested the efficacy and safety of BoNT on 25 people with oily skin. BoNT (abo-BNT, total dose of 30-45 IU) was injected into ten points on the forehead, resulting in significantly high patient satisfaction and reduced sebum production. Min et al randomly assigned 42 subjects with forehead wrinkles to receive 10 or 20 units of BoNT at five distinct injection locations. Both groups received BoNT treatment, which resulted in a considerable sebum decrease at the injection site, with a sebum gradient surrounding the injection point. At 16 weeks, both treatment groups' sebum production returned to normal levels, and efficacy did not improve significantly with greater injection doses.

The mechanism by which intradermal BoNT injection results in decreased sebum production is not entirely known because the influence of the nervous system and acetylcholine on sebaceous glands is not thoroughly described. BoNT's neuromodulatory effects are most likely to target the arrector pili muscles and local muscarinic receptors in the sebaceous glands. In vivo, the nicotinic acetylcholine receptor 7 (nAchR7) was expressed in human sebaceous glands, and acetylcholine signalling increased lipid synthesis in a dose-dependent manner in vitro. ${ }^{11}$ More research is needed to determine who the most significant candidates are and the optimum injection procedures and doses (Figure 1A and B).

\section{BoNT in Rosacea and Facial Flushing}

Rosacea is a common inflammatory dermatosis marked by facial flushing, telangiectasia, papules, pustules, and erythema. Oral medicine, laser therapy, and topicals are routinely used to treat face flushing, although they do not always work. Another unpleasant menopausal symptom is facial flushing. Several studies have shown that BoNT can help with menopausal hot flashes and rosacea. ${ }^{12-14}$ BoNT's impact on the Dermatology Life Quality Index (DLQI) of facial flushing patients was investigated in future pilot research. ${ }^{15}$ BoNT was injected into the cheeks once, up to a total dose of 30 units, resulting in a significant decrease in DLQI at two months. BoNT significantly reduced the mean number of menopausal hot flashes at day 60 , according to 



Figure I Upper image (A) of a patient with markedly oily skin, while on the opposite pole, inferior image (B) of the same patient after 2 sessions of BoNT shows significant improvement. (Technique: 100 units, $2.5 \mathrm{~mL}$ of intra-dermal BoNT-A was injected over forehead in one sitting. Total two similar sessions 30 days apart were administered. The good clinical response persisted for 6 months).

Odo et al. ${ }^{12}$ The effects of abo-BoNT were also studied in 15 rosacea patients. 15-45 IU of BoNT was injected into the face three months later, resulting in a statistically significant erythema improvement. ${ }^{13}$ In the studies, adverse effects were mentioned infrequently.

BoNT's flushing enhancement is one possible reason for its robust suppression of acetylcholine release from peripheral autonomic neurons of the cutaneous vasodilatory system. ${ }^{16,17}$ Inflammatory mediators such as calcitonin gene-related peptide (CGRP) and substance P (SP) are also inhibited by BoNT, which is well-known. ${ }^{18}$ The erythema may fade away if local skin inflammation is reduced and controlled. To assess the BoNT's role in rosacea, extensive, controlled, randomized studies are needed. BoNT injections for face flushing have additional advantages in that they reduce the pull of the facial depressors, which improves fine lines and wrinkles.

\section{BoNT in Scar Prevention}

Many people nowadays recognize the importance of active scar avoidance in postoperative scar treatment. The tension that acts on the wound edges during the healing process is a critical component that defines the final cosmetic look of a surgical scar. ${ }^{19,20}$ BoNT provides for near-complete removal of dynamic muscular strain on the healing wound by preventing acetylcholine neurotransmitter release from peripheral nerves. BoNT's tension-relieving characteristics, as well as its direct inhibitory effects on fibroblasts and TGF-1 expression, suggest that it could be used to avoid surgical scars. ${ }^{21-23}$ BoNT's anti-inflammatory effect and its effect on the cutaneous vasculature decrease the inflammatory phase of the wound healing process (from 2 to 5 days), which may help prevent scarring.
BoNT is useful in scar prevention in a variety of studies. $^{24-27}$ In an RCT, the safety and efficacy of early postoperative BoNT injection were assessed in 15 thyroidectomy scar patients. ${ }^{24}$ Fresh scars (within ten days of thyroidectomy) were given a single dose of either BoNT (20-65 IU) or $0.9 \%$ saline (control), with the BoNT-treated halves demonstrating significantly superior scar scores and patient satisfaction than the saline-treated sides. Gassner et $\mathrm{al}^{25}$ investigated if injecting BoNT into the face after forehead lacerations and excisions healed facial scars. Within 24 hours, BoNT (15-45 IU) was injected into post-op scars after wound closure to enhance cosmesis and wound healing, compared to a placebo (normal saline) injection.

\section{Rhytides}

Dynamic and static rhytides are formed by overactive musculature, photodamage, and aging, and patients perceive them as making them look tired or angry. Facial rhytides can be treated to offer people a more relaxed and refreshed appearance. The FDA currently has an exclusive authorization for BoNT for the treatment of periorbital and glabellar lines. BoNT is used off-label for the treatment of masseter hypertrophy, gummy smile, platysmal bands of the neck, mandibular border, dimpled chin, horizontal forehead lines, downturned smile, perioral lines, horizontal nasal lines and ptotic brow and with clinical results lasting about three months $^{28,29}$ (Figure 2A and B).

\section{Psychological Improvement}

BoNT enhances patient mood and perceived confidence when used in conjunction with rhytide decrease. Improvements in the FACE-Q score have been observed after treatment of moderate-to-severe glabellar lines. Even after 120 days, when the clinical effects of BoNT should be 

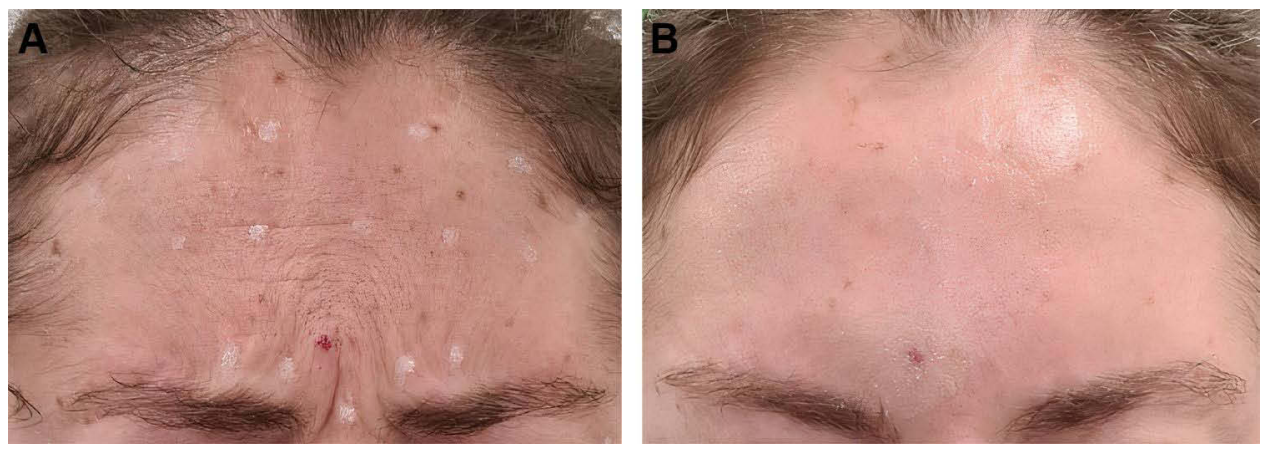

Figure 2 Pre-botox superior image (A) of a case shows horizontal forehead lines and glabellar lines giving the subject angry look, on the other hand, inferior image (B) of the same case after two sessions of botox clears away those lines with ease. (Technique: 36 units, $0.9 \mathrm{~mL}$ of intra-dermal BoNT-A was injected over forehead in one sitting. Skin pencil was used to mark the injection sites prior to therapy. Total two similar sessions were given 30 days apart).

diminishing, patients have reported improved psychological well-being and improved facial attractiveness.

Instead of automatically reinjecting BoNT every three months to have the best clinical and psychological response, practitioners should talk to patients about when retreatment is essential. ${ }^{30,31}$ Furthermore, BoNTs have been used successfully to prevent and treat migraines in neurology, with an improvement in patient quality of life and well-being ${ }^{32}$ (Figure $3 \mathrm{~A}$ and $\mathrm{B}$ ).

The FDA-approved commercially available BoNT is listed in Table 1.

\section{Role of BoNT in Dermatology Alopecia}

Alopecia areata, androgenetic alopecia, cephalalgic alopecia and radiation-induced alopecia have all been treated with BoNT-A. Although the exact mechanism by which BoNT helps hair regrowth is uncertain, it is assumed that by decreasing microvascular pressure by relaxing muscles, oxygen supply to hair follicles may be improved. Throughout $1-12$ sessions, $30-150 \mathrm{U}$ is injected into the frontal, periauricular, temporal and occipital muscles (Figure 4A and B).

Although most studies show a clinical improvement in density or growth of hair and high patient satisfaction, further RCTs are needed to determine the actual effect of BoNT on hair growth. ${ }^{33-35}$ Multiple BoNT injections for forehead wrinkles, on the other hand, have been linked to the onset of frontal alopecia. ${ }^{36}$

\section{Psoriasis}

Several studies have suggested that the neurological system plays a role in psoriasis, with high nerve fiber concentration in psoriatic skin and higher sensory nerve derived CGRP and SP levels. As a result, clinical evidence indicating that psoriasis remits following the loss of innervation are growing, nervous system injury or nerve function supports this hypothesis. ${ }^{37}$ BoNT-A reduces nerve-derived CGRP and
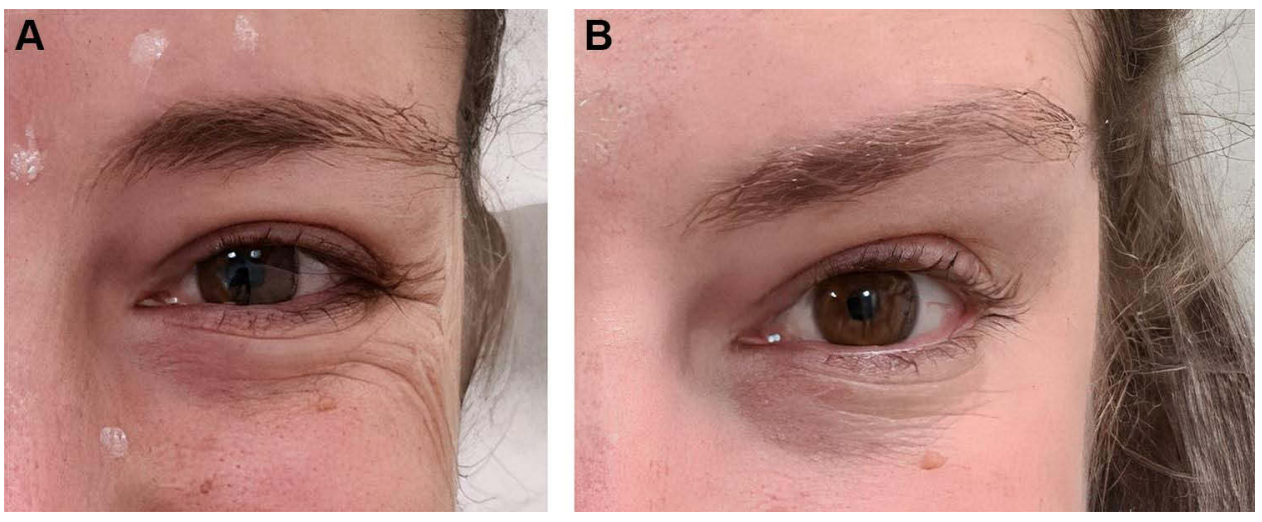

Figure 3 Superior image (A) of a subject shows lateral periorbital lines giving aged and tired look, on the other hand, inferior image (B) of the same case after a session of botox eliminates those lines and elevates the lateral eyebrow to give glance. This subject also expressed enriched emotional health succeeding this sitting. (Technique: 16 units, $0.4 \mathrm{~mL}$ of intra-dermal BoNT-A was injected per lateral periorbital region in one sitting. Only one session culminated in dramatic response which persisted for 4 months). 
Table I Commercially Available BoNT and Its Characteristics

\begin{tabular}{|l|l|l|}
\hline Commercially Available Toxin \& Serotype & FDA Approval & $\begin{array}{l}\text { Molecular Weight (kDa); Units } \\
\text { per Vial }\end{array}$ \\
\hline PrabotulinumtoxinA-xvfs (PRA; Jeuveau ${ }^{\mathrm{TH}}$ ) \& A & Cosmetic: glabellar lines & $900 ; 100$ \\
\hline IncobotulinumtoxinA (INCO; Xeomin ${ }^{\circledR}$ ) \& A & $\begin{array}{l}\text { Medical: blepharospasm, cervical dystonia. } \\
\text { Cosmetic: glabellar lines. }\end{array}$ & $150 ; 100$ \\
\hline OnabotulinumtoxinA (ONA; Botox*) \& A & $\begin{array}{l}\text { Medical: axillary hyperhidrosis, blepharospasm, } \\
\text { migraine, strabismus, } \\
\text { Cosmetic: glabellar lines, periocular rhytides }\end{array}$ & $900 ; 100$ \\
\hline AbobotulinumtoxinA (ABO; Dysport ${ }^{\circledR}$ ) \& A & $\begin{array}{l}\text { Medical: blepharospasm, cervical dystonia. } \\
\text { Cosmetic: glabellar lines. }\end{array}$ & $300-500 ; 500$ \\
\hline Rimabotulinumtoxin (RIMA; Myobloc ${ }^{\circledR}$ ) \& B & Medical: cervical dystonia & $700 ; 5000$ \\
\hline
\end{tabular}

SP release, which may explain the subjective clinical observation of disease improvement in inverse psoriasis after treatment with the drug. ${ }^{38}$ In adult KC-Tie2 mice, intradermal injections of BoNT-A resulted in a considerable reduction in cutaneous lymphocyte infiltration and a significant acanthosis improvement compared to placebo. ${ }^{37}$ However, there are few published clinical reports and observational studies, and none of them is placebo controlled. In 15 inverse psoriasis patients, Zanchi et $\mathrm{al}^{38}$ reported a favorable response to the BoNT-A treatment; however, the outcomes were assessed using patient self-assessment and an


Figure 4 Left half of clinical photograph (A) shows type 6 male-pattern hair loss according to adopted Norwood-Hamilton classification in a 34-year-old male. In contrast, same patient after 12 sessions of botox showed down-grading to type $3 \mathrm{~V}$ on culmination (B). (Technique: 100 units, $2.5 \mathrm{~mL}$ of intra-dermal BoNT-A was injected in top of the head region in one sitting. Total 12 similar sessions 15 days apart resulted in acceptable clinical response which persisted for 4 months). infiltration photographic evaluation and erythema. As a result, Chroni et $\mathrm{al}^{39}$ noted various concerns about the study, including the lack of a quantitative metric to estimate improvement (such as a PA score). The authors postulated that BoNT-A has a favorable effect in lowering local sweating in folds, such as Hailey-Hailey disease, where the efficacy of BoNT-A is due to sweating decrease. ${ }^{40-42}$ The capacity of BoNT-A to prevent algogenic neuropeptide liberation, however, resulted in a reduction in pain and itch for the patients. ${ }^{43}$

\section{Bullous Skin Disease}

Off-label, BoNT has been used to treat a variety of bullous skin diseases such as linear IgA bullous dermatosis, Weber-Cockayne disease and Hailey-Hailey disease. BoNT-A injections, oral tacrolimus, yttrium aluminum garnet ablative laser, BoNT-A with erbium have been used to treat Hailey-Hailey disease in the inframammary, axillae, groin, and intergluteal cleft regions. After treatment, there is improvement in clinical signs, with doses ranging from 25 to $200 \mathrm{U}$ every 3 to 6 months. ${ }^{42,44}$ In the case of reports, a middle-aged female with regional epidermolysis bullosa simplex had $50 \mathrm{U}$ per axilla injected into her foot, and $100 \mathrm{U}$ was injected into the foot of a young patient with linear IgA bullous dermatosis. ${ }^{45,46}$

\section{Darier Disease}

The first use of BoNT-A as adjuvant therapy in Darier illness was reported in 2007 when Kontochristopoulos et al ${ }^{47}$ effectively treated a 59-year-old patient's submammary regions. In another case from 2008, sweating decrease in the intertriginous area was beneficial in a young child with severe 
anogenital involvement. ${ }^{48}$ Her concomitant infection was treated with acitretin $10 \mathrm{mg}$ per day and antibiotic and antifungal medicines, but her low quality of life and discomfort persisted. Both symptoms and clinical lesions improved significantly after three weeks of BoNT-A injections.

\section{Eccrine Nevus}

Eccrine nevus is a rare cutaneous hamartoma characterized by an increase in the number of eccrine glands but no vascular development. The eccrine nevus differs from other disorders like angiomatous eccrine hamartoma because of this last feature. ${ }^{49}$ Eccrine nevus is most commonly found on the forearms, with minimal skin problems but a localized hyperhidrosis area. ${ }^{50}$ Surgical excision or topical medications are the most popular treatments, depending on the size covered and the hyperhidrosis entity. Honeyman et $\mathrm{al}^{51}$ documented a 12year-old child with a congenital eccrine nevus of the right wrist resistant to topical antiperspirants. Due to the magnitude of the tumor and its anatomical position, surgical excision was ruled out. Hyperhidrosis makes it challenging to participate in social and intellectual activities. The researchers chose to inject $5 \mathrm{U}$ of BoNT-A at $0.5-1 \mathrm{~cm}$ interval. The authors did not say when the first reaction to BoNT-A treatment occurred, but they did say that a year later, they noticed a considerable sweat episode reduction to once a month and the quality of life of the patients was increased. Lera et $\mathrm{al}^{49}$ treated an eccrine nevus patient on the forearm who had a low quality of life and an HDSS score of 3 on the hyperhidrosis disease severity scale (HDSS) (severe). BoNT-A (100 IU) was reconstituted in a $2.5 \mathrm{~mL}$ sterile saline solution containing $0.9 \%$ sodium chloride and given into the minor iodine test area. After 48 hours, the patient noticed a decrease in sweating, with the best outcomes at week three. The HDDS score fell to one. Because of relapse in sweating, the BoNT-A treatment was repeated after nine months. In the treatment of eccrine angiomatous hamartoma, an injections therapy of BoNT-A is useful. ${ }^{52}$ Despite the condition's rarity, it is simple to see how critical it is for these people to have a viable therapy option.

\section{Hidradenitis Suppurativa}

Hidradenitis suppurativa (HS) is a chronic skin disease characterized by painful, scarring, sinus tracts, fistulas, inflamed nodules and deep-seated in apocrine gland-bearing parts of the body in the latter stages. ${ }^{53}$ The pathophysiology of the condition is still unknown, and previously accepted hypotheses of HS development are now being challenged. The occlusion of the hair follicle is crucial in the symptoms of HS, although the mechanism that causes occlusion is unknown. Skin lesions develop in HS as a result of subsequent inflammation and a combination of innate and adaptive immunological dysfunction. ${ }^{54}$ A study by Feito-Rodriguez et $\mathrm{al}^{55}$ reported that the BoNT-A was successfully treated the prepubertal HS in 6-year-old girl. A case report by Shi et al ${ }^{56}$ observed that the BoNT-A was successfully treated the stage -3 HS in 41-yearold female. Recently, a study by Grimstad et $\mathrm{al}^{57}$ assessed whether intradermal injection with BoNT-B is an effective treatment for HS among 20 patients. The DLQI in the BoNT-B group improved from a median of 17 at baseline to 8 at 3 months, compared to a decrease from 13.5 to 11 in the placebo group.

\section{Notalgia Paresthetica}

Notalgia paresthetica (NP) is a persistent sensory neuropathy affecting the interscapular area, particularly the T2-T6 dermatomes, with itching on the upper back and cutaneous symptoms linked with rubbing and scratching. BoNT-A may help with localised pruritus by blocking the release of substance $P$, a pain and itch mediator. ${ }^{58}$ A case report by Weinfeld ${ }^{59}$ evaluated the efficacy of BoNT-A among two cases. Both are successfully treated with the BoNT-A. A study by PerezPerez et $\mathrm{al}^{58}$ assesses efficacy of BoNT-A among five patients diagnosed with NP. After the delivery of intradermal BoNT, a variety of effects were seen. There was no complete relief of the pruritus in any of the individuals. A randomized controlled trial (RCT) by Maari et a ${ }^{60}$ evaluated the efficacy and safety of BoNT-A in patients with NP in a Canadian dermatology research clinic between July 2010 and November 2011. This study was not able to confirm the beneficial effect of BoNT-A injected intradermally at doses of at most $200 \mathrm{U}$ to reduce pruritus in patients with NP.

\section{Pompholyx}

Pompholyx, also known as dyshidrotic eczema, is a recurrent vesicular-bullous illness that affects the palms and soles. Although the pathophysiology of this condition is unknown, it is now thought to be a symptom of atopic dermatitis. ${ }^{61}$ Wet works, sweating, and occlusion are the most common inciting elements. ${ }^{62}$ Wearing gloves or shoes causes pain, burning, itching, and discomfort in patients; bacterial infections are prevalent. Swartling et $\mathrm{al}^{61}$ found that patients treated with BoNT-A for palmar hyperhidrosis improved their hand eczema. In 2002, they presented the results of a study involving ten individuals with bilateral vesicular hand dermatitis; one hand was treated with BoNT-A injections, while the other hand served as a control at the follow-up. The treatment had a good or excellent effect on 7 out of 10 patients. In 
six patients, Wollina and Karamfilov ${ }^{63}$ employed topical corticosteroids on both hands and intracutaneous injections of $100 \mathrm{U}$ of BoNT-A on the most severely affected hand. In hand treated with combination therapy, the authors discovered a quick reduction in itching and vesiculation, and they attributed BoNT-A efficacy in pompholyx to its anhidrotic action as well as its suppression of SP.

\section{Raynaud's Phenomenon}

Vasospasm of the digits, also known as Raynaud's syndrome, is challenging to treat and often resistant to first-line medications such as bosentan, iloprost, phosphodiesterase inhibitors, nitrates, and calcium channel blockers. Surgical procedures that involve recovery and downtime, such as sympathectomy, are invasive. Raynaud's phenomenon of the fingers, both primary and sclerosis-related, has been successfully treated with BoNT injection. ${ }^{64,65}$ Investigators noticed that 13 patients experienced rapid pain relief, and chronic ulcers healed within 60 days after receiving 50-100 $\mathrm{U}$ of BoNT-A injections in 19 Raynaud's phenomenon patients. ${ }^{66}$ After six weeks, digital pulp temperature in the fingertips treated with BoNT dramatically improved compared to normal saline injections, indicating that BoNT is beneficial in treating Raynaud's phenomenon-associated vasospasm. ${ }^{67}$ For the time being, there are no standardized injection procedures in use; injections in the digits, wrist or distal metacarpus did not result in significantly different clinical outcomes, according to one study, despite the fact that they were all effective in treating Raynaud's phenomenon-associated vasospasm. ${ }^{68}$

\section{Hyperhidrosis}

50-100 U of BoNT-A per axilla, administered intradermally in a grid-like design, can be used to treat primary axillary hyperhidrosis. Clinical outcomes are visible within one week and last for 3 to 10 months. Most patients are satisfied with their treatment. Patients should be advised that compensatory sweating can occur in up to $5 \%$ of cases. ${ }^{69,70}$ BoNT is also effective for treating palmar and plantar hyperhidrosis (Figure 5A and $\mathrm{B}$ ).

With 2-3 injection locations per digit, injections should be placed $1 \mathrm{~cm}$ apart in a grid-like arrangement. BoNT-A can be given to each hand in the range of 75-100 units and to each foot in 100-200 units. Clinical results can take up to a week to manifest and can last for three to six months. Patients should be informed about the potential side effects of BoNT injections in their palms and feet before starting treatment. Patients may report weakness after a palmar injection. On the other hand, plantar injections may make walking difficult, especially if a nerve block is done before BoNT treatment. ${ }^{71,72}$ Unfortunately, $20 \%$ of patients with plantar hyperhidrosis who get BoNT injections do not react to treatment. ${ }^{72}$

BoNT has been used to treat hyperhidrosis in new ways in recent research. In one case, a male patient with pressure-induced ulceration received $100 \mathrm{U}$ of BoNT-A injected into the gluteal cleft every 6-8 months to reduce sweat production and concomitant wound maceration; skin integrity was preserved over two years with no clinical deterioration of the pressure injury. ${ }^{73}$ Another study used $2250 \mathrm{U}$ of BoNT-B injected in a band-like pattern across the occipital scalp, parietal scalp, frontal scalp, and forehead, as well as perioral and periocular areas, to treat postmenopausal craniofacial hyperhidrosis. Patients who received BoNT-B had a 91\% improvement in the DLQI three weeks following therapy, compared to an $18 \%$ decline in quality of life with placebo injections. ${ }^{74}$ In treating sialorrhoea and Frey's syndrome, the BoNT injection is effective. Otolaryngologists frequently conduct treatment due to the anatomic position of injections. ${ }^{75,76}$

\section{Chromhidrosis and Bromhidrosis}

Pigmented sweat could be markedly unsettling condition for patients. Though this disorder is quite rare; facial and axillary involvement can add to patient's plight. Numerous
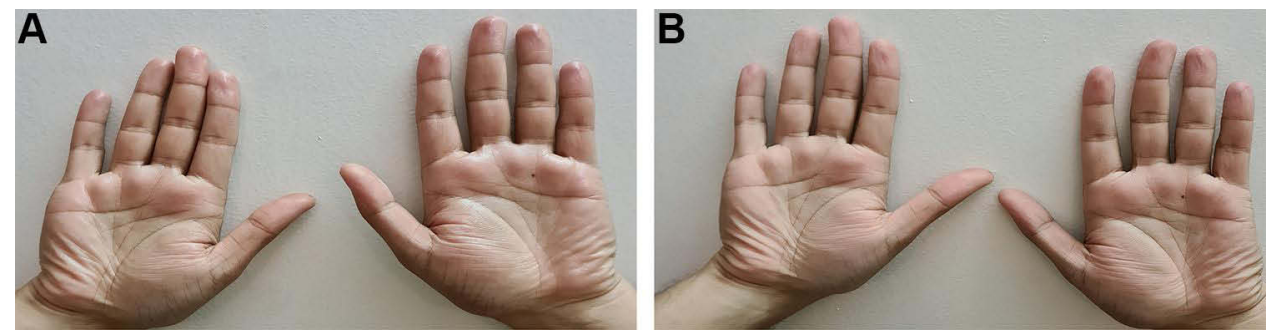

Figure 5 Superior clinical image (A) shows diffuse palmar hyperhidrosis in a young college student feeling anxious about the disorder and not responding to medical treatment. Similar patient after a botox therapy demonstrated complete resolution of hyperhidrosis (B). (Technique: After confirmation with starch iodine test; I00 units, $2.5 \mathrm{~mL}$ of intra-dermal BoNT-A was injected per hand in one sitting. Total two similar sessions 15 days apart resulted in dramatic response which persisted for 6 months). 
case reports and publications have demonstrated positive outcome after BoNT-A injections within just seven days. ${ }^{77-79}$

Obnoxious smell from axillary hyperhidrosis, bromhidrosis could be embarrassing as well socially repellent. This could even have negative impact on mental space and confidence of the patient. Recently, Wu et al reported near complete elimination of bad smell from axilla after intracutaneous BoNT-A injections. ${ }^{80}$ In another contemporary, prospective study; 62 adolescents with dermatological diagnosis of primary axillary bromhidrosis were enrolled. $82.25 \%$ patients perceived notable abatement of malodour when their axillary regions were subjected with BoNT-A injections. ${ }^{81}$

\section{Multiple Eccrine Hidrocystomas (Meh)}

Meh is identified by single or multiple benign cystic lesions in middle-aged females, predominantly in centrofacial region with protracted course and seasonal fluctuations. Meh is usually seen in sunny conditions and linked with hyperhidrosis. Many researchers have observed exceptional results in these cases after perilesional injections of BoNT-A. ${ }^{82}$

\section{Post-Herpetic Neuralgia}

Post-herpetic neuralgia (PHN) is the most frequent neurological complication of Herpes Zoster infection, which is more common in more than 60 years of age. BoNT-A imparts its pan inhibition directly on the local nerve ending as well as through modulation of microglial-astrocyticneuronal crosstalk. Numerous studies noticed remarkable attrition in sleep scores and quality of life in those patients with at least $30 \%$ to $50 \%$ decrement in pain on treating with BoNT-A. ${ }^{83}$

\section{Lichen Simplex Chronicus}

Lichen simplex chronicus is described as excessive focal itching without any obvious reason. This can be enormously debilitating to patient. Clinical dermatological examination shows lone erythematous patch with increased skin markings and excoriations. Recent landmark study from Egypt demonstrated that BoNT-A can be safe and effective treatment in localized recalcitrant pruritus of lichen simplex chronicus, hypertrophic lichen planus, lichen planus, burns, inverse psoriasis, and postherpetic neuralgia. ${ }^{84}$

\section{Keloids}

Keloids are aberrant tissue scarring occurring after the injury. Keloids have genetic association and many therapies have been tried on them with limited success. However, none of them is completely curative. Although intralesional corticosteroids remain the main stay of treatment, intralesional BoNT-A have become an excellent alternative in recent days. BoNT-A can reduce the levels of TGF- $\beta 1$ and CTGF, which will ultimately attenuate fibroblast differentiation. Multiple studies have demonstrated therapeutic success of BoNT-A in keloid cases. In fact, two case series of keloid patients even reported $100 \%$ response with very high patient satisfaction with the use intralesional BoNT-A injections. ${ }^{85}$

\section{Pachyonychia Congenita}

Pachyonychia congenita is a rare genetic disease with hyperkeratosis of soles, hypertrophy of nails and hyperhidrosis. Few researchers have concluded that BoNT-A injections not only improve hyperhidrosis, but it can also lead to reduction in pain and discomfort. ${ }^{86,87}$

\section{Aquagenic Keratoderma}

Aquagenic keratoderma is an uncommon condition in which patients suffer from thickened, white pebbly of soles and palms on exposure to water along with itching. Several case reports in literature showed successful treatment and improvement after BoNT-A therapy, also in resistant cases. ${ }^{88}$

\section{Adverse Effects and Complications Associated with the BoNT}

Bleeding, edema, erythema, and pain at the injection sites are all possible BoNT adverse effects. ${ }^{89}$ By using thinner needles and diluting BoNT with saline, these side effects can be prevented. BoNT injections can cause headaches; however, they usually go away after 2-4 weeks. Systemic analgesics can be used to address this side effect. ${ }^{90,91}$ Nausea, malaise, influenza-like symptoms, and ptosis are some of the other side effects that have been recorded. ${ }^{89}$ Ptosis is a side effect of using BoNT to treat the glabellar area. It is produced by localized BoNT diffusion, which might last for weeks but can be addressed with alpha-adrenergic agonist ophthalmic drops. When BoNT is injected into the lower eyelids, it can cause ectropion due to the local diffusion process. In addition, patients who receive BoNT injections to cure crow's feet or bunny lines (periorbital) may develop strabismus as 
a result of inadvertent injection of BoNT and localized BoNT diffusion. ${ }^{89,92}$ Nonetheless, as the toxin's paralyzing effect wears off, all of these side effects will fade away. ${ }^{93,94}$

Cosmetic BoNT injections have a low risk of complications. Ecchymosis and purpura are the most prevalent consequences, which can be reduced by applying cold to the injection sites before and after the BoNT injection. ${ }^{90,91}$ BoNT should be injected in low doses, at least $1 \mathrm{~cm}$ from the inferior, superior, or lateral margins of the orbital bone, with the appropriate dose. Patients should not manipulate the injected areas for 2-3 hours after therapy and sit or stand upright for 3-4 hours after treatment. ${ }^{95}$

\section{Future Direction}

BoNT-A in various novel formulations is currently being tested to treat glabellar and periocular lines. Topical and injectable daxibotulinumtoxinA has been investigated, but the topical formulation was shown to be ineffective. Injectable DAXI has entered FDA Phase III trials, demonstrating efficacy in the treatment of glabellar lines and clinical outcomes that could last up to 5 weeks longer than onabotulinumtoxinA. ${ }^{96}$ LetibotulinumtoxinA is now available in Asia and studied for FDA approval to treat periorbital rhytides. ${ }^{97}$ LetibotulinumtoxinA has a more significant concentration of neurotoxic protein per volume than incobotulinumtoxinA, but it also has a higher quantity of inactive neurotoxin, increasing the immunoreaction risk. ${ }^{98}$

Liquid BoNT-E is being studied in addition to novel BoNT-A formulations because of its purportedly faster onset of action and shorter clinical results duration (1430 days). EB-001 has been found to decrease the appearance of the glabellar lines safely and effectively and improve the cosmesis of forehead scars following Mohs micrographic surgery. ${ }^{99}$ Dermatologists may be permitted to use these books. Pharmaceutical companies are pursuing BoNT-A formulations for off-label therapy of dermatologic medical conditions in addition to the current aesthetic purposes.

\section{Conclusion}

BoNT is a highly adaptable injectable medicine that can be used to treat a wide range of skin disorders, including Hidradenitis suppurativa, psoriasis, bullous skin disorders, abnormal scarring, hair loss, and hyperhidrosis and keloids. In cosmetic applications, BoNT is considered safe and effective for reduction of facial wrinkles, especially in the uppermost third of the face. BoNT A is well known for its use in the cosmetic world to reduce wrinkles. Although BoNT is usually safe, it is always vital to be aware of injection places because the toxin might disperse and negatively affect areas that should not have been treated. Clinicians should be aware of sitespecific complications when injecting BoNT into the feet, hands, or neck. Dermatologists need to be acquainted with both the on- and off-label uses of BoNT to provide patients with pertinent treatment and decrease associated morbidity. BoNT's clinical efficacy in an off-label setting, as well as any potential long-term safety concerns, should be assessed by well-designed clinical trials.

\section{Data Sharing Statement}

Data sharing is not applicable to this article as no datasets were generated or analysed during the current study.

\section{Compliance with Ethics Guidelines}

The examination of the patients was conducted according to the principles of the Declaration of Helsinki. The author certifies that she has obtained all appropriate patient consent forms, in which the patients gave their consent for images and other clinical information to be included in the journal. Patients understand that their names and initials will not be published, and due effort will be made to conceal their identity.

\section{Author Contributions}

Dr. Piyu Parth Naik solely contributed to manuscript writing. The author made substantial contributions to conception and design, acquisition of data, and interpretation of data; took part in drafting the article or revising it critically for important intellectual content; agreed to submit to the current journal; gave final approval of the version to be published; and agreed to be accountable for all aspects of the work.

Authorship: The named author met the International Committee of Medical Journal Editors (ICMJE) criteria for authorship for this article, takes responsibility for the integrity of the work, and has given her approval for this version to be published.

\section{Funding}

This article was self-funded, and no other source of funding present.

\section{Disclosure}

Dr. Piyu Parth Naik reports no conflicts of interest for this work. 


\section{References}

1. Huang W, Foster JA, Rogachefsky AS. Pharmacology of botulinum toxin. J Am Acad Dermatol. 2000;43(2):249-259. doi:10.1067/ mjd.2000.105567

2. Hanna E, Pon K. Updates on botulinum neurotoxins in dermatology. Am J Clin Dermatol. 2020;21(2):157-162. doi:10.1007/s40257-01900482-2

3. Fonfria E, Maignel J, Lezmi S, et al. The expanding therapeutic utility of botulinum neurotoxins. Toxins. 2018;10(5):208. doi:10.3390/toxins 10050208

4. Ramachandran R, Yaksh TL. Therapeutic use of botulinum toxin in migraine: mechanisms of action. Br J Pharmacol. 2014;171 (18):4177-4192. doi:10.1111/bph.12763

5. Juhász M, Hosking A-M, Mesinkovska N. Botulinum toxins in medical and cosmetic dermatology. EMJ Dermatol. 2021. doi:10.33590/ emjdermatol/20-00202

6. Guida S, Farnetani F, Nisticò SP, et al. New trends in botulinum toxin use in dermatology. Dermatol Pract Concept. 2018:277-282. doi: $10.5826 / \mathrm{dpc} .0804 \mathrm{a} 05$.

7. Chen S. Clinical uses of botulinum neurotoxins: current indications, limitations and future developments. Toxins. 2012;4(10):913-939. doi:10.3390/toxins 4100913

8. Arora G, Arora S. Where and how to use botulinum toxin on the face and neck - indications and techniques. Cosmoderma. 2021;1(17):17. doi:10.25259/CSDM_16_2021

9. Min P, Xi W, Grassetti L, et al. Sebum production alteration after botulinum toxin Type A injections for the treatment of forehead rhytides: a prospective randomized double-blind dose-comparative clinical investigation. Aesthetic Surg J. 2015;35(5):600-610. doi:10.1093/asj/sju150

10. Rose AE, Goldberg DJ. Safety and efficacy of intradermal injection of botulinum toxin for the treatment of oily skin. Dermatol Surg. 2013;39(3):443-448. doi:10.1111/dsu.12097

11. Li ZJ, Park SB, Sohn KC, et al. Regulation of lipid production by acetylcholine signalling in human sebaceous glands. J Dermatol Sci. 2013;72(2):116-122. doi:10.1016/j.jdermsci.2013.06.009

12. Odo MEY, Odo LM, Farias RV, et al. Botulinum toxin for the treatment of menopausal hot flushes. Dermatol Surg. 2011;37 (11):1579-1583. doi:10.1111/j.1524-4725.2011.02109.x

13. Bloom BS, Payongayong L, Mourin A, Goldberg DJ. Impact of intradermal abobotulinumtoxina on facial erythema of rosacea. Dermatol Surg. 2015;41(Supplement 1):S9-S16. doi:10.1097/ DSS.0000000000000277

14. Geddoa E, Matar HE, Paes TRF. The use of botulinum toxin-A in the management of neck and anterior chest wall flushing: pilot study. Int J Dermatol. 2013;52(12):1547-1550. doi:10.1111/ijd.12200

15. Eshghi G, Khezrian L, Alirezaei P. Botulinum toxin A in treatment of facial flushing. Acta Med Iran. 2016;454-457. Available from: http:// acta.tums.ac.ir/index.php/acta/article/view/4983.

Accessed September 8, 2021.

16. Kellogg DL. In vivo mechanisms of cutaneous vasodilation and vasoconstriction in humans during thermoregulatory challenges. $J$ Appl Physiol. 2006;100(5):1709-1718. doi:10.1152/ japplphysiol.01071.2005

17. Kellogg DL, Pèrgola PE, Piest KL, et al. Cutaneous active vasodilation in humans is mediated by cholinergic nerve cotransmission. Circ Res. 1995;77(6):1222-1228. doi:10.1161/01.RES.77.6.1222

18. Carmichael NME, Dostrovsky JO, Charlton MP. Peptide-mediated transdermal delivery of botulinum neurotoxin type A reduces neurogenic inflammation in the skin. Pain. 2010;149(2):316-324. doi:10.1016/j.pain.2010.02.024

19. Lee B-J, Jeong J-H, Wang S-G, Lee J-C, Goh E-K, Kim H-W. Effect of botulinum toxin Type A on a rat surgical wound model. Clin Exp Otorhinolaryngol. 2009;2(1):20. doi:10.3342/ceo.2009.2.1.20
20. Wolfram D, Tzankov A, Pülzl P, Piza-Katzer H. Hypertrophic scars and keloids - a review of their pathophysiology, risk factors, and therapeutic management. Dermatologic Surg. 2009;35(2):171-181. doi:10.1111/j.1524-4725.2008.34406.x

21. Zhibo X, Miaobo Z. Botulinum toxin type A affects cell cycle distribution of fibroblasts derived from hypertrophic scar. $J$ Plast Reconstr Aesthetic Surg. 2008;61(9):1128-1129. doi:10.1016/j. bjps.2008.05.003

22. Zhibo X, Miaobo Z. Potential therapeutical effects of botulinum toxin type A in keloid management. Med. Hypotheses. 2008;71(4):623. doi:10.1016/j.mehy.2008.04.018

23. Xiao Z, Zhang F, Lin W, Zhang M, Liu Y. Effect of botulinum toxin Type $A$ on transforming growth Factor $\beta 1$ in fibroblasts derived from hypertrophic scar: a preliminary report. Aesthetic Plast Surg. 2010;34 (4):424-427. doi:10.1007/s00266-009-9423-z

24. Kim YS, Lee HJ, Cho SH, Lee JD, Kim HS. Early postoperative treatment of thyroidectomy scars using botulinum toxin: a split-scar, double-blind randomized controlled trial. Wound Repair Regen. 2014;22(5):605-612. doi:10.1111/wrr.12204

25. Gassner HG, Brissett AE, Otley $\mathrm{CC}$, et al. Botulinum toxin to improve facial wound healing: a prospective, blinded, placebo-controlled study. Mayo Clin Proc. 2006;81(8):1023-1028. doi:10.4065/81.8.1023

26. Wilson AM. Use of botulinum toxin Type A to prevent widening of facial scars. Plast Reconstr Surg. 2006;117(6):1758-1766. doi:10.1097/01.prs.0000209944.45949.d1

27. Ziade M, Domergue S, Batifol D, et al. Use of botulinum toxin type A to improve treatment of facial wounds: a prospective randomised study. J Plast Reconstr Aesthetic Surg. 2013;66(2):209-214. doi:10.1016/j.bjps.2012.09.012

28. Carruthers J, Carruthers A. Practical cosmetic botox techniques. J Cutan Med Surg. 1999;3(4_suppl):S4-49-S4-52. doi:10.1177/ 12034754990030 S409

29. Draelos ZD. Cosmetic Dermatology: Products and Procedures. John Wiley \& Sons; 2015.

30. Chang BL, Wilson AJ, Taglienti AJ, Chang CS, Folsom N, Percec I. Patient perceived benefit in facial aesthetic procedures: FACE-Q as a tool to study botulinum toxin injection outcomes. Aesthetic Surg J. 2016;36(7):810-820. doi:10.1093/asj/sjv244

31. Cohen JL, Kaufman J, Peredo MI, Down R, Mashburn J. Assessment of psychological well-being after abobotulinumtoxin A treatment: a comparison of 2 reconstitution volumes. Dermatologic Surg. 2020;46(2):289-292. doi:10.1097/DSS.0000000000001940

32. Burstein R, Blumenfeld AM, Silberstein SD, Manack Adams A, Brin MF. Mechanism of action of Onabotulinumtoxin A in chronic migraine: a narrative review. Headache J Head Face Pain. 2020;60 (7):1259-1272. doi:10.1111/head.13849

33. Cho H-R, Lew B-L, Lew H, Sim W-Y. Treatment effects of intradermal botulinum toxin Type A injection on alopecia areata. Dermatologic Surg. 2010;36(Supplement 4):2175-2181. doi:10.1111/j.1524-4725.2010.01709.x

34. Hyun MY, Kim BJ, Lee C, Kim JW. Radiation-induced alopecia treated with Botulinum toxin type a injection. Plast Reconstr Surg Glob Open. 2014;2:10. doi:10.1097/GOX.0000000000000149

35. Shon U, Kim MH, Lee DY, Kim SH, Park BC. The effect of intradermal botulinum toxin on androgenetic alopecia and its possible mechanism. $J$ Am Acad Dermatol. 2020;83(6):1838-1839. doi:10.1016/j.jaad.2020.04.082

36. Di Pietro A, Piraccini BM. Frontal alopecia after repeated botulinum toxin type A injections for forehead wrinkles: an underestimated entity? Ski Appendage Disord. 2016;2(1-2):67-69. doi:10.1159/ 000448380

37. Ward NL, Kavlick KD, Diaconu D, Dawes SM, Michaels KA, Gilbert E. Botulinum Neurotoxin A decreases infiltrating cutaneous lymphocytes and improves acanthosis in the KC-Tie2 mouse model. J Invest Dermatol. 2012;132(7):1927-1930. doi:10.1038/jid.2012.60 
38. Zanchi M, Favot F, Bizzarini M, Piai M, Donini M, Sedona P. Botulinum toxin type A for the treatment of inverse psoriasis. $J$ Eur Acad Dermatology Venereol. 2008;22(4):431-436. doi:10.1111/ j.1468-3083.2007.02457.x

39. Chroni E, Monastirli A, Tsambaos D. Botulinum toxin for inverse psoriasis? J Eur Acad Dermatology Venereol. 2009;23(8):955. doi:10.1111/j.1468-3083.2009.03143.x

40. Bagherani N, Smoller BR. The efficacy of botulinum toxin type A in the treatment of Hailey-Hailey disease. Dermatol Ther. 2016;29 (6):394-395. doi:10.1111/dth.12346

41. Lapiere JC, Hirsh A, Gordon KB, Cook B, Montalvo A. Botulinum toxin type A for the treatment of axillary Hailey-Hailey disease Dermatol Surg Br Commun. 2000;26(4):371-374. doi:10.1046/ j.1524-4725.2000.99278.x

42. Ho D, Jagdeo J. Successful botulinum toxin (onabotulinumtoxinA) treatment of Hailey-Hailey disease. J Drugs Dermatol. 2015;14 (1):68-70.

43. Gilbert E, Ward NL. Efficacy of botulinum neurotoxin type A for treating recalcitrant plaque psoriasis.. J Drugs Dermatol. 2014;13 (11): 1407-1408.

44. Bedi M, Taylor AL. Recalcitrant Hailey-Hailey disease responds to oral tacrolimus and botulinum toxin type A. Cutis. 2015;96(6):E14 E16.

45. Abitbol RJ, Zhou LH. Treatment of epidermolysis bullosa simplex, Weber-Cockayne type, with botulinum toxin type A. Arch Dermatol. 2009;145(1):13-15. doi:10.1001/archdermatol.2008.546

46. Legendre L, Maza A, Almalki A, Bulai-Livideanu C, Paul C, Mazereeuw-Hautier J. Botulinum toxin A: an effective treatment for linear immunoglobulin A bullous dermatosis located in the Axillae. Acta Derm Venereol. 2016;96(1):122-123. doi:10.2340/000155552178

47. Kontochristopoulos G, Katsavou AN, Kalogirou O, Agelidis S, Zakopoulou N. Botulinum toxin type A: an alternative symptomatic management of Darier's disease. Dermatol Surg. 2007;33 (7):882-883.

48. Santiago-et-Sanchez-Mateos JL, Bea S, Fernandez M, Perez B, Harto A, Jaen P. Botulinum toxin type A for the preventive treatment of intertrigo in a patient with Darier's disease and inguinal hyperhidrosis. Dermatol Surg. 2008;34(12):1733-1737.

49. Lera M, Espana A, Idoate MA. Focal hyperhidrosis secondary to eccrine naevus successfully treated with botulinum toxin type A. Clin Exp Dermatol. 2015;40(6):640-643. doi:10.1111/ced.12608

50. Kawaoka JC, Gray J, Schappell D, Robinson-Bostom L. Eccrine nevus. J Am Acad Dermatol. 2004;51(2):301-304. doi:10.1016/j. jaad.2003.12.030

51. Honeyman JF, Valdes R, Rojas H, Gaete M. Efficacy of botulinum toxin for a congenital eccrine naevus. $J$ Eur Acad Dermatol Venereol. 2008;22(10):1275-1276. doi:10.1111/j.1468-3083.2008. 02630.x

52. Nygaard U, Dalager S, Spaun E, Hedelund L. Large eccrine angiomatous hamartoma: a novel clinical presentation of disease. J Dermatol Case Rep. 2015;9(3). doi:10.3315/jdcr.2015.1211

53. Dufour DN, Emtestam L, Jemec GB. Hidradenitis suppurativa: a common and burdensome, yet under-recognised, inflammatory skin disease. Postgrad Med J. 2014;90(1062):216-221. doi:10.1136/ postgradmedj-2013-131994

54. Prens E, Deckers I. Pathophysiology of hidradenitis suppurativa: an update. J Am Acad Dermatol. 2015;73(5):S8-S11. doi:10.1016/j. jaad.2015.07.045

55. Feito-Rodríguez M, Sendagorta-Cudós E, Herranz-Pinto P, de Lucaslaguna R. Prepubertal Hidradenitis suppurativa successfully treated with botulinum toxin A. Dermatologic Surg. 2009;35(8):1300-1302. doi:10.1111/j.1524-4725.2009.01231.x

56. Shi W, Schultz S, Strouse A, Gater DR. Successful treatment of stage III hidradenitis suppurativa with botulinum toxin A. BMJ Case Rep. 2019;12(1):e226064. doi:10.1136/bcr-2018-226064
57. Grimstad O, Kvammen BØ, Swartling C. Botulinum toxin Type B for Hidradenitis Suppurativa: a randomised, double-blind, placebo-controlled pilot study. Am J Clin Dermatol. 2020;21 (5):741-748. doi:10.1007/s40257-020-00537-9

58. Pérez-Pérez L, García-Gavín J, Allegue F, Caeiro JL, Fabeiro JM, Zulaica A. Notalgia paresthetica: treatment using intradermal botulinum toxin A. Actas Dermo-Sifiliográficas. 2014;105(1):74-77. doi:10.1016/j.adengl.2013.09.003

59. Weinfeld PK. Successful treatment of notalgia paresthetica with botulinum toxin Type A. Arch Dermatol. 2007;143(8):980. doi:10.1001/archderm.143.8.980

60. Holmes AD. Potential role of microorganisms in the pathogenesis of rosacea. J Am Acad Dermatol. 2013;69(6):1025-1032. doi:10.1016/j. jaad.2013.08.006

61. Swartling C, Naver H, Lindberg M, Anveden I. Treatment of dyshidrotic hand dermatitis with intradermal botulinum toxin. $J$ Am Acad Dermatol. 2002;47(5):667-671. doi:10.1067/mjd.2002.124605

62. Wollina U. Pompholyx. Am J Clin Dermatol. 2010;11(5):305-314. doi:10.2165/11533250-000000000-00000

63. Wollina U, Karamfilov T. Adjuvant botulinum toxin A in dyshidrotic hand eczema: a controlled prospective pilot study with left-right comparison. J Eur Acad Dermatology Venereol. 2002;16(1):40-42. doi:10.1046/j.1468-3083.2002.00361.x

64. Herrick AL. The pathogenesis, diagnosis and treatment of Raynaud phenomenon. Nat Rev Rheumatol. 2012;8(8):469-479. doi:10.1038/ nrrheum.2012.96

65. Smith L, Polsky D, Franks AG. Botulinum toxin-A for the treatment of Raynaud syndrome. Arch Dermatol. 2012;148(4):426-428. doi:10.1001/archdermatol.2011.1144

66. Neumeister MW, Chambers CB, Herron MS, et al. Botox therapy for ischemic digits. Plast Reconstr Surg. 2009;124(1):191-201. doi:10.1097/PRS.0b013e3181a80576

67. Jenkins SN, Neyman KM, Veledar E, Chen SC. A pilot study evaluating the efficacy of botulinum toxin A in the treatment of Raynaud phenomenon. $J$ Am Acad Dermatol. 2013;69(5):834-835. doi:10.1016/j.jaad.2013.06.029

68. Fregene A, Ditmars D, Siddiqui A. Botulinum toxin type A: a treatment option for digital ischemia in patients with Raynaud's phenomenon. J Hand Surg Am. 2009;34(3):446-452. doi:10.1016/j. jhsa.2008.11.026

69. Cote TR, Mohan AK, Polder JA, Walton MK, Braun MM. Botulinum toxin type A injections: adverse events reported to the US Food and Drug Administration in therapeutic and cosmetic cases. $J$ Am Acad Dermatol. 2005;53(3):407-415. doi:10.1016/j.jaad.2005.06.011

70. Doft MA, Kasten JL, Ascherman JA. Treatment of axillary hyperhidrosis with botulinum toxin: a single surgeons experience with 53 consecutive patients. Aesthetic Plast Surg. 2011;35(6):1079-1086. doi:10.1007/s00266-011-9738-4

71. Klein AW. Contraindications and complications with the use of botulinum toxin. Clin Dermatol. 2004;22(1):66-75. doi:10.1016/j. clindermatol.2003.12.026

72. Carruthers A, Carruthers J. Botulinum toxin type A. J Am Acad Dermatol. 2005;53(2):284-290. doi:10.1016/j.jaad.2005.03.060

73. Uhlig-Reche H, Verduzco-Gutierrez M. Treatment of secondary hyperhidrosis of the intergluteal cleft with botulinum toxin. $P M$ $R J$ Inj Funct Rehabil. 2020. Available from: https://europepmc.org/ article/med/32412168. Accessed September 8, 2021.

74. Cabreus P, Swartling C, Rystedt A. Postmenopausal craniofacial hyperhidrosis treated with botulinum toxin type B. J Dermatol. 2019;46(10):874-878. doi:10.1111/1346-8138.15029

75. Freni F, Gazia F, D'Alcontres FS, Galletti B, Galletti F. Use of botulinum toxin in Frey's syndrome. Clin. case reports. 2019;7 (3):482. doi:10.1002/ccr3.2019

76. Weitzman RE, Kawai K, Nuss R, Hughes A. A 10-year retrospective review of botulinum toxin injections and surgical management of sialorrhea. Cureus. 2020;12:5. 
77. Wu JM, Mamelak AJ, Nussbaum R, McElgunn PS. Botulinum toxin $A$ in the treatment of chromhidrosis. Dermatol Surg. 2005;31:963-965. doi:10.1097/00042728-200508000-00014

78. Beer K, Oakley H. Axillary chromhidrosis: report of a case, review of the literature and treatment considerations. J Cosmet Dermatol. 2010;9:318-320. doi:10.1111/j.1473-2165.2010.00530.x

79. He J, Wang T, Dong J. A close positive correlation between malodor and sweating as a marker for the treatment of axillary bromhidrosis with botulinum toxin A. J Dermatol Treat. 2012;23:461-464. doi:10.3109/09546634.2011.594869

80. Wu CJ, Chang CK, Wang CY, Liao YS, Chen SG. Efficacy and safety of botulinum toxin A in axillary bromhidrosis and associated histological changes in sweat glands: a prospective randomized double-blind side-by-side comparison clinical study. Dermatol Surg. 2019;45:1605-1609. doi:10.1097/DSS.0000000000001906

81. Wang T, Dong J, Long-Term Safety HJ. Efficacy of botulinum toxin A treatment in adolescent patients with axillary bromhidrosis. Aesthet Plast Surg. 2018;42:560-564. doi:10.1007/s00266-018-1075-4

82. Al-Ghamdi AS, Alghanemy N, Joharji H, et al. Botulinum toxin: non cosmetic and off-label dermatological uses. J Dermatol Dermatol Surg. 2015;19(1):1-8. doi:10.1016/j.jdds.2014.06.002

83. Ri S, Kivi A, Wissel J. The safety and effect of local Botulinumtoxin A injections for long-term management of chronic pain in post-herpetic neuralgia: literature review and cases report treated with incobotulinumtoxin A. Journal of Personalized Medicine. 2021;11(8):758. doi:10.3390/jpm11080758

84. Gharib K, Mostafa A, Elsayed A. Evaluation of botulinum toxin Type A injection in the treatment of localized chronic pruritus. $J$ Clin Aesthet Dermatol. 2020;13(12):12-17.

85. Sohrabi C, Goutos I. The use of botulinum toxin in keloid scar management: a literature review. Scars Burns Healing. 2020;6:205951312092662. doi:10.1177/2059513120926628

86. Thomas BR, Sahota A. Pachyonychia congenita and botulinum toxin. Br J Dermatol. 2020;182:531-532. doi:10.1111/bjd.18784

87. Koren A, Sprecher E, Reider E, Artzi O. A treatment protocol for botulinum toxin injections in the treatment of pachyonychia congenita-associated keratoderma. $\mathrm{Br} \quad J \quad$ Dermatol. 2020;182:671-677. doi:10.1111/bjd.18169

88. Rodríguez-Villa Lario A, Vega-Díez D, González-Cañete M, et al. Aquagenic keratoderma with dorsal involvement treated with botulinum toxin. Case report and review of literature. Dermatol Ther. 2020;33:e14347. doi:10.1111/dth.14347
89. Jensen JD, Freeman SR, Cohen JL. Botulinum toxins. Cosmet Dermatol Prod Proced. 2015;364-374.

90. Ascher B, Talarico S, Cassuto D, et al. International consensus recommendations on the aesthetic usage of botulinum toxin type A (Speywood Unit) - part II: wrinkles on the middle and lower face, neck and chest. J Eur Acad Dermatol Venereol. 2010;24 (11):1285-1295. doi:10.1111/j.1468-3083.2010.03728.x

91. De Maio M, Rzany B. Botulinum Toxin in Aesthetic Medicine. Springer Science \& Business Media; 2007.

92. Cox SE, Adigun CG. Complications of injectable fillers and neurotoxins. Dermatol Ther. 2011;24(6):524-536. doi:10.1111/ j.1529-8019.2012.01455.x

93. Ogden S, Griffiths TW. A review of minimally invasive cosmetic procedures. $\mathrm{Br} J$ Dermatol. 2008. doi:10.1111/j.13652133.2008.08845.x

94. Klein AW. Complications, adverse reactions, and insights with the use of botulinum toxin. Dermatologic Surg. 2003;29(5):549-556.

95. Rzany B, Zielke H. Safety of botulinum toxin in aesthetic medicine. In: de Maio M, Rzany B, editors. Botulinum Toxin in Aesthetic Medicine. New York: Springer-Verlag Berlin Heidelberg; 2007:119-125.

96. Bertucci V, Solish N, Kaufman-Janette J, et al. DaxibotulinumtoxinA for injection has a prolonged duration of response in the treatment of glabellar lines: pooled data from two multicenter, randomized, double-blind, placebo-controlled, Phase 3 studies (SAKURA 1 and SAKURA 2). J Am Acad Dermatol. 2020;82(4):838-845. doi:10.1016/j.jaad.2019.06.1313

97. Hugel. Evaluate the safety and efficacy of botulax ${ }^{\circledR}$ as compared to botox ${ }^{\circledR}$ in subject with moderate to severe crow's feet lines; 2017. Available from: https://clinicaltrials.gov/ct2/show/NCT03408236. Accessed September 8, 2021.

98. Frevert J, Ahn KY, Park MY, Sunga O. Comparison of botulinum neurotoxin type A formulations in Asia. Clin Cosmet Investig Dermatol. 2018;11:327. doi:10.2147/CCID.S160723

99. Yoelin SG, Dhawan SS, Vitarella D, Ahmad W, Hasan F, Abushakra S. Safety and efficacy of EB-001, a novel type E botulinum toxin, in subjects with glabellar frown lines: results of a Phase 2, randomized, placebo-controlled, ascending-dose study. Plast Reconstr Surg. 2018;142(6):847e-855e. doi:10.1097/ PRS.0000000000005029

\section{Publish your work in this journal}

Clinical, Cosmetic and Investigational Dermatology is an international, peer-reviewed, open access, online journal that focuses on the latest clinical and experimental research in all aspects of skin disease and cosmetic interventions. This journal is indexed on CAS.
The manuscript management system is completely online and includes a very quick and fair peer-review system, which is all easy to use. Visit http://www.dovepress.com/testimonials.php to read real quotes from published authors. 